\title{
LA JUNTA DE INFORMACIÓN EN MADRID PARA LAS REFORMAS EN LAS ANTILLAS, 1866
}

por

\author{
M. ${ }^{a}$ Dolores Domingo ACEBRón \\ Depto. de Historia Contemporánea. \\ Instituto de Historia, CSIC
}

RESUMEN: La Junta de Información convocada en 1866 por las autoridades españolas reúne en Madrid a los antillanos y a los representantes oficiales con un tema principal y fundamental: hablar sobre la situación de Cuba y Puerto Rico. Sus quejas y peticiones son muy concretas, no ofreciendo duda sobre lo que quieren los cubanos y los puertorriqueños. Por un lado, la abolición de la esclavitud y por otro, una mayor libertad política. En definitiva, una serie de reformas sociales, económicas y políticas. Ante esto las autoridades españolas muestran un talante demasiado inflexible e intransigente que no facilita el entendimiento entre antillanos y españoles. La respuesta de las autoridades españolas ante dichas propuestas fue un aumento en el sistema de impuestos mediante una contribución directa y la negativa a abolir las aduanas. En la cuestión política quedaba de manifiesto la defensa a ultranza del mantenimiento del «statu quo». Los comisionados antillanos comprueban en Madrid el desinterés de la Metrópoli para afrontar los problemas de Cuba y Puerto Rico. La situación se convierte en irreversible con el inicio del proceso emancipador con un objetivo conseguir la independencia del colonialismo español.

Palabras clave: España. Cuba. Puerto Rico. Política colonial. Reformas. S. XIX.

ABSTRACT: The Junta de Information organised in 1866 by the Spanish authorities brought together in Madrid official representatives and people from the Antilles to discuss an essential topic: the situation of Cuba and Puerto Rico. Their complaints and petitions were specific, leaving no doubt as to what Cubans and Puerto Ricans desired. They wished for, on the one hand, the abolition of slavery, and on the other, greater political freedom: in sum, a series of social, economic and political reforms. In reponse, the Spanish autborities displayed an inflexible and intransigent disposition, which did not belp the understanding between Antillas and the Spanish. The Spa- 
nish authorities responded by increasing direct taxes and rejecting the abolition of customs. On the political front, Spain maintained its extreme defense of the "statu quo». The commissioners from the Antilles found confirmed in Madrid the metropolis's lack of interest towards Cuban and Puerto Rican problems. The situation became irreversible once the independence movement had begun, wibt the objective of achieving freedom from Spanish colonialism.

KeY WORDS: Spain. Cuba. Puerto Rico. Colonialism. Reforms. Nineteenth century.

\section{1. ¿POR QUÉ SE CONVOCA LA JUNTA DE INFORMACIÓN?}

La Constitución democrática de 1812 y más tarde el régimen constitucional de 1820, posibilita la presencia de los diputados en Madrid de los territorios americanos y de la lejana Filipinas ${ }^{1}$. Restaurada la nueva Constitución en Cuba los efectos son inmediatos, el General Manuel Lorenzo liberal,.- que mantiene estrechas vinculaciones con el grupo de Juan Alvarez Mendizabal.en la Península, es nombrado gobernador de Santiago de Cuba y Comandante del Departamento Oriental2 ${ }^{2}$ - sin consentimiento del Capitán General en La Habana, el General Tacón.- proclama la Constitución en Santiago de Cuba. Sin consultar nada más que a su conciencia, concede una serie de libertades, la de prensa, forma ayuntamientos de caracter constitucional, crea la Milicia urbana. Envía a Madrid a Porfirio Valiente como representante de todas las Corporaciones. Su conducta duramente recriminada y censurada. Tacón se encarga de que las aguas vuelvan a su cauce; es decir, pacificar el territorio que se había insurreccionado. Los servicios cumplidos son recompensados con la concesión de los títulos de Marqués de la Unión de Cuba y Vizconde de Bayamo.

En 1834 cuando se proclama el Estatuto real base del derecho monárquico constitucional, quedan establecidas dos cámaras, la de diputados y la de Senadores $^{3}$. En Cuba a pesar de la nueva normativa jurídica que plantea el Estatuto Real, continua en vigor la ley que concede facultades omnímodas a los Capitanes Generales. Se afianzan las famosas comisiones militares. Cuba y Puerto Rico por un decreto de Fernando VII, se encontraban bajo un régimen que otorgaba a los militares facultades omnímodas y carecían de representación en las Cor-

\footnotetext{
1 Los diputados cubanos fueron Andrés de Jauregui y Juan Bernardo O Gavan. Cifr: TORRES Cuevas, Eduardo, BARCIA, Carmen y García, Gloria: Historia de Cuba. La Colonia (evolución económica y formación nacional de los orígenes hasta 1867). La Habana, Editora Política, 1994, pág. 328.

2 Ibidem, pág. 350

3 Valie de SAn Juan, Maa Angeles, Pérez, Sampeiro, Angela: Póceres y Senadores (1824-1923). Madrid, Senado, Secretaría General Dirección de Estudios y Documentación, 1993, 554 págs. Ver asimismo: Estadística del Personal y Vicisitudes de las Cortes y de los Ministerios de España.(Desde el 29 de septiembre de 1833 hasta el 24 de diciembre de 1879). Madrid, Imprenta y Fundición de la Viuda e Hijos de J. A. García, 1880, 1220 págs.
}

Hispania, LXII/1, núm. 210 (2002) 141-166 
tes, desde que en 1837 los diputados habían sido expulsados. Al estar sometidas ambas islas a las «leyes especiales»".

Los diputados cubanos elegidos en las Cortes de 1836, presentan en 1837 una protesta. La situación es bastante delicada al quedar fuera de las Cortes los representantes de las provincias de Ultramar. Cuyas necesidades particulares son desconocidas por los propios diputados en Madrid. En algunas ocasiones los diputados autonomistas habían sido acusados de independentistas. Es decir, en el Congreso se desvirtúan los hechos o se falsean, en aras de la «integridad del territorio». No se persiguen los abusos de poder. Sí a pesar de todo, se condena a Cuba a «la triste condición de colonia, sus diputados se consolarían con el triste testimonio de su recto proceder y con el recuerdo indeleble de haber defendido a su patria»s.

"Las Comisiones de reforma de la Constitución y en especial de Ultramar», integradas por Agustín Argüelles, Vicente Sancho, y Martín de los Heros, ${ }^{6}$ son bastante explícitas. «Sí a la Isla de Cuba se le daban derechos políticos ella se declararía independiente; los diputados de las provincias de Ultramar emplearían el elemento de libertad como medio de ilustración y romperían los lazos que la unían a la Metrópoli»?

El 18 de abril de 1837 las Cortes aprueban que no al no ser posible aplicar la Constitución adoptada para la Península a las provincias ultramarinas de América y Asia, estas se regirían por «leyes especiales». La exclusión de la Cámara de los diputados antillanos tiene graves consecuencias: en primer lugar, con esa decisión se siembra el germen que fructifica en los movimientos independentistas que producen la separación de Cuba y de Puerto Rico de la Metrópoli. Los desprecios y los desaires, se interpretan como una provocación. En segundo lugar, hostigan la división entre peninsulares y criollos ${ }^{8}$. En tercer lugar, durante todo el S. XIX se producen quejas constantes de los sectores más libera-

4 PIN̄EYRo, Enrique: Como acabó la dominación de España en América. París, Garnier hermanos, libreros editores, págs. 21-24. Ver también, FigueroA MERCADO, Loida: Puerto Rico ante la oferta de Leyes Especiales por España. Tesis Doctoral, Universidad Central de Madrid, Facultad de Filosofía y Letras, Madrid, 1963.

5 Los diputados cubanos firmantes fueron: Juan Montalvo y Castillo, Francisco de Armas y José Antonio Saco. Madrid, 21-II-1837. Cifr: Información sobre reformas de Cuba y Puerto Rico. Nueva York, Imprenta de Hallet y Breen, 1867, tomo 1, Introducción, pág. XXI.

6 Eran además miembros de estas comisiones Antonio González, Manuel Joaquín Tarancón, Joaquín $\mathrm{M}^{\mathrm{a}}$ Ferrer, Mauricio Carlos Onís, Pedro Antonio Acuña, Manuel $\mathrm{M}^{\mathrm{a}}$ Acevedo, Jacinto Felix Domenech, Alvaro Gómez, Pablo Torrens y Miralda, Antonio Flores Estrada y Pio Laborda, Cifr: Ibidem, pág. XXII.

7 Intervención de Argüelles. Cifr: Ibidem, pág. XXIII

8 «La patria esclavizada, entronizados los abusos, convertida la Isla en campo de explotación, puesta en venta la justicia y desoídas las quejas, los cubanos amaban su patria, se dejaron llevar por la desesperación, perdieron toda esperanza de mejora para el porvenir a la sombra de la Metrópoli, lanzándose a empresas desgraciadas que dieron lugar a sangrientas represiones y a hacer aún más duro el yugo que oprimía al país.» Cifr: Ibidem. 
les hasta los más oficialístas que tienen como objetivo denunciar la situación que se vive tanto en Cuba como en Puerto Rico.

No obstante desde 1837 hasta 1876 se aplaza la aplicación de las «leyes especiales» para Ultramar. Las cuales nunca serán promulgadas. Era bastante novedoso dotar a las colonias de un marco político específico. Pero estas «leyes especiales» se convirtieron «en la suma de la inhibición del desarrollo del ordenamiento liberal y la premeditada prolongación y acentuación del poder casi ilimitado de los capitanes generales en las tres posesiones ultramarinas. Las «leyes especiales» eran en realidad la inexistencia de leyes, especiales u ordinarias»?.

En un contexto político internacional inestable: con la triple intervención en México, la guerra de Secesión; la anexión de Santo Domingo a la Corona española. Por su parte en Cuba la llegada de capitanes generales más liberales produce un ambiente más propicio para los cambios. Por ejemplo, el capitán General Concha en 185310; o el Capitán General Francisco Serrano desde 1859 hasta 1862 impulsa una serie de reformas que abarca el fomento de la instrucción pública, la prensa; incluso se permiten manifestaciones políticas, inspiradas en la tolerancia ${ }^{11}$. Le sucede el General Dulce en 1869 que continua las reformas. Persigue el tráfico negrero. Construye escuelas gratuitas superiores. Enfrentándose con los sectores ultra-conservadores de la más rancia burocracia colonial, y con los Cuerpos de Voluntarios ${ }^{12}$, los cuales consiguen en 1869 destituirle por la fuerza del cargo de Capitán General de la Isla. Serrano y Dulce se convierten en los gobernadores generales que con más firmeza apoyaron medidas que tendieran a solucionar los graves problemas de la gran Antilla.

En 1854 algunos conservadores tan significados como el director del Diario de la Marina, Araujo de Lira, o Sabino Obejero, uno de los más importantes comerciantes, y Julián Zulueta reconocido traficante negrero, presentan una exposición a las Cortes pidiendo que Cuba pudiera enviar sus representantes a Madrid.

Convencidos de lo justo de sus peticiones los reformistas envían el 28 de julio de 1865 la Exposición de los reformistas a S.M. (Apéndice $\mathrm{n}^{\circ} 1$ ). Meses más tarde el 25 de noviembre de 1865 con Narváez al frente de la Unión Liberal y como Ministro de Ultramar, Antonio Canovas del Castillo, se aprueba el decreto convocando en Madrid una Junta de Información para discutir las bases de las leyes especiales previstas para Cuba y Puerto Rico desde 1837. La decisión fue

\footnotetext{
9 Fradera, Josep $\mathrm{M}^{\mathrm{a}}$ : «¿Por qué no se promulgaron las «Leyes Especiales» de Ultramar?». En FRADERA, Josep Ma: Gobernar colonias. Barcelona, Ediciones Península, págs. 71-93.

10 GutierRez De LA CONCHA, José: Memorias sobre el estado político, gobierno y administración de la Isla de Cuba. Madrid, Editor J. Trujillo, 1853, 41 págs.

11 Serrano había declarado: «sí la suerte de los cubanos no mejoraba tendrían razón para sublevarse». Cifr: CABRERA, Raimundo: Cuba y sus jueces. Filadelfía. La Compañía Levitype impresores y grabadores, 1891, págs. 318-319.

12 Domingo ACEBRÓN, $\mathrm{M}^{\mathrm{a}}$ Dolores: Los Voluntarios y su papel contrarrevolucionario en la Guerra de los Diez Años en Cuba, 1868-1878. París, L'Harmattan, págs. 83-94.
} 
acogida con satisfacción por los liberales. Los conservadores la miraron con recelo. En Cuba el trabajo de concienciación había sido propiciado por el periódico El Siglo dirigido por el Conde de Pozos Dulces, siendo este además el órgano del Partido reformista ${ }^{13}$. Por su parte, en Puerto Rico la inexistencia de partidos políticos, la elección de los comisionados respondía a dos tendencias: reformistas y antirreformistas. La situación de la pequeña Antilla era bastante diferente compuesta en su mayoría por hombres libres, la población esclava estaba constituida por una minoría. Las elecciones para elegir los comisionados fueron un rotundo triunfo para los reformistas. Sin embargo, derrocada la Unión liberal, es sustituido por un ministerio moderado. El nuevo gabinete no parece mostrar demasiado interés. Al fin y al cabo esto suponía el fracaso del gobierno anterior. El nuevo gobierno por el Real Decreto de 11 de agosto de 1866 designa otros comisionados José Ramón Fernández y Juan Bautista Machicote defensores del «tatu quo» que no asistirían después a la Junta en Madrid ${ }^{14}$.

\section{INTEGRANTES DE LA JUNTA DE INFORMACIÓN. TENDENCIAS POLÍTICAS}

El Real Decreto el 25 de noviembre de 1865 no menciona a Las Filipinas ni al resto de las colonias en el Pacífico. Luis Prudencio Alvarez, residente en Las Filipinas desde 1825 y miembro de la Audiencia de Manila, que no pudo ocupar su puesto en Las Cortes, denuncia en 1837 los resultados tan nefastos de la política colonial en Las Filipinas... ${ }^{15}$

La explicación de la marginación de Las Filipinas habría que buscarla en las diferencias entre Cuba y Puerto Rico y aquellas. Tenían un modelo muy distinto. Su organización social, económica y hacendística hacían de ellas una «colonia peculiar» ${ }^{16}$. En 1866 la Hacienda filipina sufre una fuerte crisis ${ }^{17}$ No era el

13 MORAles y MORAles, Vidal: Biografía del Sr. Francisco Frias y Jacott, Conde de Pozos Dulces. La Habana, La Propaganda Literaria, 1887, 35 págs.

14 RUZ Belvis, Segundo, ACOSTA, José Julián y QuiÑONES, Francisco Mariano: Proyecto para la abolición de la esclavitud en Puerto Rico. San Juan de Puerto Rico, Instituto de Cultura Puertorriqueña, 1959, págs.16-17.

15 FRADERA, Josep María: Filipinas. La colonia más peculiar. (La Hacienda pública en la definición de la política colonial, 1762-1868). Madrid, C.S.I.C, 1999, pág. 267. Ver también para un periodo posterior MALLO, Tomás: «La cuestión de las Filipinas. Labra y el Ateneo de Madrid» en El Ateneo, Revista Científica, Literaria y Artística, Madrid, cuarta época, 1997, págs. 87-100.

16 Fueron hasta comienzos del S. XIX «la plataforma de un fuerte mercado internacional entre las grandes economías asiáticas, de Nueva España y de Europa: y el hecho principal de que se trataba de un mundo campesino sometido a un sistema tributario filipino había obtenido sus ingresos del comercio transpacífico, de los impuestos personales, del tributo indígena...Sin olvidar, la importancia que había tenido la centralidad de los estancos del tabaco...» FrADERA, Josep María, Op cit, pág. 291.

17 Gabriel Alvarez, un alto funcionario de la colonia, envió a Canovas un informe detallado de la información, Ibidem, pág. 287. 
momento más propicio para abordar reformas. Sin olvidar, que también las Filipinas habían sufrido la expulsión de sus representantes.

El Real Decreto en tan sólo dos artículos; pretendía tratar algunas de las cuestiones más importantes: la cuestión social, la cuestión económica y la cuestión política.

El primer apartado aborda la reglamentación del trabajo de la población de color y asiática, y los medios de facilitar la inmigración. El segundo, sobre los tratados de navegación y comercio y las reformas en el sistema arancelario y el régimen de Aduanas.

El Gobierno se proponía que concurrieran a la Junta de Información veintidós comisionados elegidos por los ayuntamientos de las dos Islas, los senadores que las representaban, las autoridades principales que habían ejercido cargos en ellas y un número de personas igual al de los comisionados de los ayuntamientos los cuales tuvieran un conocimiento de las necesidades y aspiraciones de las Antillas.

Los comisionados por Cuba fueron los siguientes: Por La Habana: Manuel de Armas, y Antonio X, San Martín (este candidato tenía como opositor al Conde de Pozos Dulces el cual triunfó por 50 votos contra 47). Por Matanzas: José Luis Alfonso, marqués de Montelo, su renuncia hizo que se eligiera a José $M^{a}$ Angulo y Heredia; por Santiago de Cuba: José Antonio Saco; por Pinar del Rio, Manuel Ortega; por Colón: José Antonio Echevarría; por Puerto Príncipe: Calixto Bernal; por Cienfuegos: Tomás Terry; por Villaclara: Antonio Fernández Bramosio, que había sido elegido por Cárdenas optó por esta jurisdicción, siendo nombrado en su lugar el Conde de Pozos Dulces; por Holgüín: Juan Munné; por Sagua: conde de Vallellano; por Cárdenas: Antonio Fernández Bramosio; por Remedios: José Morales Lemús; por Güines, Nicolás Azcárate; por SanctiSpíritus: Agustín Camejo; y por Guanajay: Antonio Rodríguez Ojea.

Por Puerto Rico, José Julián Acosta y Francisco Quiñones por Mayagüez y San Germán ; Segismundo Ruiz Belvis por San Juan de Puerto Rico y Manuel P. Zeno por Arecibo. De los cuales Acosta y Quiñones eran liberales, Zeno era conservador y Ruiz Belvis separatista. Debido a lo cual los conservadores intentaron que fuera impugnada la elección, pero no lo consiguieron.

José Julían Acosta es un reformista que apoyaba la abolición de la esclavitud y que se le relacionaba con Angel Quintero del cual había recibido la influencia política que profesaba. Siendo tachado de anti-español y expulsado de la Isla en 1862. ${ }^{18}$ Acosta se había formado en las Universidades de Madrid, París y Berlín. En dicha ciudad conoce a Humboldt. Asimismo en París estuvo en contacto con Betances. En 1846 viaja a Madrid con Román Baldorioty y Castro donde se licenció en Ciencias Matemáticas. En la capital de España frecuenta a los cubanos y principalmente a Domingo del Monte. Comienza a tra-

18 Figueroa Mercado, Loida: Puerto Rico ante la oferta de las Leyes Especiales por España. Tesis doctoral. Universidad Central de Madrid, Facultad de Filosofía y Letras, Madrid, 1963, fol. 4.

Hispania, LXII/1, núm. 210 (2002) 141-166 
bajar sobre la historia de Puerto Rico que apareció con el nombre Biblioteca Histórica de Puerto Rico. En 1853 de regreso a Puerto Rico publica un ensayo titulado: Cuestión de brazos, para el cultivo actual de las tierras de Puerto Rico, donde aparecen sus ideas abolicionistas. Unos años después en 1862 Acosta realiza la edición anotada de la famosa obra de Fay Iñigo Abad: Historia geográfica civil y natural de la isla de Puerto Rico ${ }^{19}$.

En lo que respecta a Manuel Zeno ${ }^{20}$ defendía el sistema esclavista e incluso se le había encomendado por los propietarios de esclavos que lo defendiera. Por el contrario Ruiz Belvis propietario era reconocido de tendencia separatista y relacionado en Mayaguëz, lugar donde hay gran número de anti-españoles, con todos aquellos que profesan estas ideas. La definición que hacían de él las autoridades españolas: "Sus ideas en la cuestión de reforma son mucho más avanzadas que lo que el orden y el Gobierno de S.M. conviene, en varias ocasiones ha sido vigilado por este Gobierno, sabedor de las ideas contrarias a la legalidad y a la justicia que reflejan las leyes, aprovechando con sagacidad las ocasiones que el contacto con el público le proporciona para infundirlas y propagarlas entre las gentes ignorantes» ${ }^{21}$. Incluso Ruiz Belvis había colaborado con Betances en la formación de una sociedad secreta para libertar a los recién nacidos y ofrecer ayuda a los esclavos prófugos ${ }^{22}$. Y al que Morales Carrión considera el más ideólogo de los puertorriqueños que participan en la Junta de Información. Sus argumentos de tipo moral para defender la abolición de la esclavitud se basan en la definición del Código de las Siete Partidas: «Servidumbre es la más vil y la más despreciada cosa que entre los hombres pueda ser» ${ }^{23}$.

El Gobierno al comprobar que la mayoría de los elegidos son partidarios de las reformas, intenta equilibrar esta situación, nombrando a destacados antirreformistas. Entre los cuales figuraron, por Cuba: José Suárez Argudín, Pedro Sotolongo, Ramón Montalvo, Nicolás Martínez Valdivieso, Mamerto Pulido, Francisco Ochoa, Joaquín González Estéfani y Miguel Antonio Herrera. Y por Puerto Rico: José Fernández y Juan Bautista Machicote. Renunciarían Pulido, Ochoa, Fernández y Machicote.

Elegidos o representantes del Gobierno, participaron en la Junta de Información Alejandro Olivan (senador y Ministro de Marina) como presidente de las reuniones, Pedro de Sotolongo, Nicolás Martínez Valdivieso, Ramón Montalvo

\footnotetext{
19 VÁsQueZ, Carmen: "José Julián Acosta, Abolicionista» en Anuario de Estudios Americanos, Escuela de Estudios Hispanoamericanos, C.S.I.C., Sevilla, 1986, vol 43, págs. 259-267.

20 Manuel Zeno era natural de Arecibo pero residia en esas fechas en Barcelona. Ibidem

21 Monclova, Lido Cruz: Historia de Puerto Rico, S. XIX. Puerto Rico, Editorial, Universitaria, Universidad de Puerto Rico, 1970, 6 vls.

22 SuÁrez Díaz, Ada: El Doctor Ramón Emeterio Betances y la Abolición de la esclavitud. San Juan, 1980, págs. 14-15. Cifr: MORAles CARRIón, Arturo: «Ojeada a las Corrientes abolicionistas en Puerto Rico» en Anuario de Estudios Americanos, Escuela de Estudios Hispanoamericanos, C.S.I.C., Sevilla, 1986, tomo 43, pág. 301.

23 Morales Carrión, Arturo, Op cit, pág. 309.
} 
y Calvo, Ramón de La Sagra, Marqués de Almendares, (senador), Gerónimo Mariano Usera (deán de la Catedral de La Habana); Vicente Vázquez Queipo, José Suárez Argudín, Joaquín González Estéfani, José Ignacio Echevarría, Joaquín $\mathrm{M}^{\mathrm{a}}$ Ruiz, Marqués de Manzanedo, José de la Cruz Castellanos, (Consejero de Instrucción Pública);Ignacio González Olivares, Domingo Sterling y Heredia ( Consejero de Administración de la Isla de Cuba); Francisco de Paula Giménez, (Director de la Sociedad mercantil de Cárdenas) Isidro Díaz Argüelles, Francisco del Corral y Francisco Cutanda (abogado).

Las personas elegidas para la Junta de Información de clara tendencia reformista ponían de manifiesto los anhelos de Cuba y Puerto Rico. Sin embargo, el periódico ultra-conservador el Diario de la Marina, se muestra contrario a lo sucedido y pide al Gobierno que el periódico El Siglo fuera clausurado pues según su punto de vista ejerce una influencia negativa en la sociedad además de atentar contra los intereses de España.Acusan directamente al director de la publicación Francisco Frías y Jacott, Conde de Pozos Dulces, elegido por el ayuntamiento de Villa Clara. En 1866 desempeña el cargo de regidor teniente de alcalde quinto en el municipio de La Habana, y es uno de los más destacados reformistas. Por este motivo el partido español hizo todo lo posible para que su candidatura no saliera ${ }^{24}$.

El Conde de Pozos Dulces ${ }^{25}$ es uno de los reformistas que lucha con mayor ahínco por sus ideales. En su tumultuosa vida tuvo que hacer frente a situaciones bastante penosas. Establecido en París desde 1842 y dedicado al estudio de las ciencias físico-químicas. Estaba en contacto con otros destacados compatriotas, Domingo del Monte y José de la Luz y Caballero ${ }^{26}$. Regresa a Cuba debido a algunos problemas familiares y comienza a tomar parte en la actividad científica y literaria de la Isla y desempeña algunos cargos en distintas corporaciones.

24 MORALES Y MORALES, Vidal, Op cit, 35 págs

25 Francisco Frias y Jacott, Conde de Pozos Dulces había nacido en La Habana el 24 de septiembre de1809. Educado en Baltimore, en 1842 se encontraba en París realizando estudios. Regresó a Cuba y en 1849 fue premiada su Memoria, La Industria pecuaria en Cuba. En 1851 fue consiliario de la Junta de Fomento. En 1854 el Gobierno le detiene en la cárcel del Morro y le destierra a Osuna (Sevilla). De nuevo en París publicará la Memoria sobre El trabajo agrícola y la población en Cuba, La Cuestión de Cuba; y en 1860 aparecería la Colección de escritos sobre agricultura, industria, ciencias y otros ramos de interés para Cuba; todos estos escritos en el destierro en París.

Cifr: MORAleS y MORALES, Vidal: Op cit, 35 págs. Sobre el tema de su estancia en París. Ver Domingo ACEBrón, Ma Dolores: «Los Reformistas cubanos en París 1838-1878» en Caravelle, Toulouse, $\mathrm{n}^{\circ} 74,2000$, págs. 105-117. Después del fracaso de la Junta de Información; y al iniciarse la Guerra de los Diez Años en 1868 emigró a París en 1869 y allí murió el 24 de octubre de 1877. Cifr: CABRERA, Raimundo: Op cit, págs. 277-278.

Ver también: PIRALA, Antonio: Anales de la Guerra de Cuba. Madrid, Ed. Felipe González Rojas, 1895, 1896, tomo 1, págs. 494-495.

26 De reciente aparición sobre José de la Luz y Caballero: La Polémica Filosófica Cubana 18381839. Ensayo introductorio, compilación y notas CONDE RODRIGUEZ, Alicia, La Habana, Biblioteca de Clásicos cubanos, Imagen Contemporánea, vol 1, 2000, 491 págs. 
La situación en Cuba está bastante alterada fracasados los intentos anexionistas del General Narciso López y ejecutado el 1 de septiembre de 1851. Es descubierta una conspiración en el pueblo de "Vuelta Abajo» implican a Pozos Dulces y de ahí su destierro a Sevilla durante dos años. Más tarde se traslada a Estados Unidos donde contacta con algunos de sus amigos, entre los que se encontraban, Gaspar Betancourt Cisneros, más conocido como «El Lugareño», José Elías Fernández y Porfirió Valiente. Participando en algunos de los trabajos de la Junta Revolucionaria de Nueva York. Disuelta la Junta regresa a París hacia 1857 o 1860, volviendo a sus estudios científicos, junto a Guillermo Arozamena e inicia una actividad como corresponsal del Correo_de La Habana. Regresa a Cuba en 1861 y comienza a dirigir el periódico El Porvenir, dedicado a las artes y la agricultura. Más tarde junto a José Quintín Suzarte colabora para fundar el periódico El Siglo que dirige durante tres años hasta que es designado para formar parte de la Junta de Información. El 29 de septiembre se embarca para Europa acompañado de otro de los comisionados por la jurisdicción de Pinar del Rio, Manuel Ortega. Hicieron escala en Nueva York, embarcándose para Francia, en París pasa varios días junto a su amigo José Silverio Jorrín. Dirigiéndose a Madrid donde se encontraban ya algunos de los comisionados. Fueron recibidos por el Duque de la Torre y Eduardo Asquerino, director de la Revista La América ${ }^{27}$; que les obsequiaron con «banquetes y saraos». Correspondían a la hospitalidad recibida por Asquerino durante su estancia en $\mathrm{Cu}$ ba: ${ }^{28} \mathrm{Al}$ iniciarse la Guerra de los Diez Años, Pozos Dulces emigra a París en 1869 y continua su labor periodística en el periódico El Americano. Muere en la ciudad de la luz el 24 de octubre de $1877 .{ }^{29} \mathrm{El}$ «testamento de su patriotismo» como dijo Manuel Sangüily, desvela el estado emocional en que vivió sus últimos años. "Muero en el desconsuelo de no ver realizado el sueño de toda mi vida: la libertad de Cuba. Espero que mis amigos no la abandonen y que jamás transijan con sus opresores» ${ }^{30}$. Junto a él otro de los más importantes intelectuales cubanos reformistas, José Antonio Saco ${ }^{31}$. En 1833 regresa a Cuba. Su trabajo es reconocido, la Sociedad Patriótica premia su Memoria sobre caminos de la Isla de Cuba y la Memoria sobre la vagancia y medios de extirparla. Además dirige la prestigiosa Revista Bimestre Cubana y el Colegio de Buena Vista. Desterrado por

27 LÓPEZ OCÓN, Leoncio: Biografía de La América. Una crónica hispano-americana del liberalismo democrático español (1857-1866). Madrid, C.S.I.C., 1987, 215 págs.

28 MORALES Y MORALES, Vidal: Op cit, 35 págs.

29 CABRERA, Raimundo: Op cit, págs. 277-278.

30 MAESTR, Raul: «El Conde de Pozos Dulces». Conferencia pronunciada en el Ateneo de La Habana, en el ciclo denominado «Maestros de la Cultura Cubana» los días 5 de julio al 9 de agosto de 1940. La Habana, Publicaciones del Ateneo de La Habana, págs. 55-70. Ver también: LECUYER, Marie Claude: Biografía del Conde de Pozos Dulces, París, L'Harmatan, 2000, vol. 20.

31 José Antonio Saco nació en Bayamo el 7 de mayo de 1797. Se educó en el Seminario de La Habana. En 1824 se dirigió a Estados Unidos y después a Europa donde fundó el periódico El Mensajero Semanal. Cifr: CABRERA, Raimundo: Op cit, págs. 281-283. 
sus actividades políticas se traslada a Inglaterra y después a Madrid; utilizando la prensa como medio de difusión de sus ideas reformistas. Elegido tres veces diputado y expulsado en 1837. Viaja por Alemania, Italia, Austria, Portugal y Suiza fijando su residencia en París y allí publica con el apoyo económico de los expatriados cubanos su famosa Historia de la esclavitud desde los tiempos más remotos hasta nuestros días. En 1861 regresa a Cuba siendo elegido en 1866 para la Junta de Información. En 1879 volverá a ser elegido de nuevo diputado por Santiago de Cuba pero no pudo su ocupar su escaño al fallecer el 26 de septiembre de $1879^{32}$.

Tanto los comisionados cubanos y puertorriqueños, sobre todo los de tendencia reformista que son convocados a Madrid para una tarea tan difícil, como es exponer los principales problemas de las Antillas, son hombres de relevancia política y de reconocido prestigio intelectual, como queda reflejado. El caso de Calixto Bernal ${ }^{33}$ establecido en Madrid publica varias obras importantes: Impresiones de un Viaje, Teoría de la autoridad, que seria traducida a varios idiomas; $E l$ Derecho, La Democratie au XIX siècle, y la Monarquía democrática, Las Colonias en la actualidad ${ }^{34}$.O la figura de Nicolás Azcárate ${ }^{35}$ en 1856 era redactor de la $R e-$ vista de Jurisprudencia y colabora en la Revista del Pueblo de Enrique Piñeyro. Su casa era el lugar de reunión de los literatos más notables. Publica los trabajos de los contertulios en el libro titulado Noches Literarias. Su participación en la Junta de Información hace que se establezca en Madrid y funde el periódico La Voz del Siglo, y desde el que defiende la urgencia de las reformas para Cuba bajo la bandera de España. Incluso se entrevista con el General Serrano, para pedirle que no olvidara las promesas hechas a los liberales cubanos ${ }^{36}$. También dirige La Constitución, ambos de talante democrático. Regresa a La Habana en 1875 en plena guerra. Sin embargo, sus posiciones contrarias a los independentistas, no evitaron ser expatriado por el General Valmaseda. No podemos olvidar su refutada posición reformista y antiesclavista. En México redacta El Eco de Ambos Mundos. Regresa a La Habana y funda y preside el Nuevo Liceo ${ }^{37}$.

Un poco dudosa ante el movimiento de independencia o por lo menos quedó bajo sospecha fue la posición de Antonio Fernández Bramosio ${ }^{38}$. Desempe-

32 Ibidem

33 Calixto Bernal nació en Puerto Principe el 14 de octubre de 1804. Abogado en 1822. Fue socio cofundador del Colegio de Abogados de Puerto Príncipe. En 1839 cuando se creó la Audiencia Pretorial de La Habana sería nombrado Abogado fiscal: Por motivos de salud tuvo que trasladarse a España y después a Europa. Cifr: CABrerA, Raimundo: Op cit, pág. 322

34 Cifr: Carta de Gabriel Millet a Rafael Ma de Labra. Sin lugar, 6-I-1886. Archivo Da Rosa de Labra. Autógrafos, segundo volumen, (1880-1892).

35 Nicolás Azcárate nació en La Habana el 21 de julio de 1828. En Madrid se licenció de Abogado en 1854 y ejerce su profesión en La Habana. Cifr: MORALES y MORALES, Vidal:Op cit, págs. 30-31.

36 Ibidem

37 CABRERA, Raimundo: Op cit, pág 321.

38 Antonio Fernández Bramosio nació en La Habana. Estudió en el Colegio de San Cristobal de La Habana donde se licenció en Derecho en 1843. Colabora en varios periódicos principalmente 
ñaba el cargo de Regidor del Ayuntamiento de Cárdenas. Pero al comenzar la guerra en 1868 viaja a Nueva York con un salvo conducto del General Dulce; a pesar de pesar sobre él un auto de prisión. Esto fue interpretado en algunos medios como «merced a las revelaciones realizadas sobre los rebeldes». Esto no ha sido confirmado ${ }^{39}$. Por el contrario no había ninguna duda sobre la posición pro independentista de José Morales Lemus ${ }^{40}$, siendo él único que participa en el movimiento de independencia encabezado por Carlos Manuel de Céspedes. Como abolicionista había dado la libertad a sus esclavos. Participa en la Conspiración de Narciso López y en la de Ramón Pintó en 1850. A su regreso a La Habana financia el periódico El Siglo. Terminados los trabajos de la Junta de Información fue uno de los primeros que opinó que los comisionados debían retirarse y elevar una protesta. A su regreso a Cuba en 1868 es acusado de infidente y se le embargan sus bienes. La República en Armas le da el cargo de Ministro Plenipotenciario en Estados Unidos ${ }^{41}$. Frente a los reformistas los defensores del «statu quo» Mamerto Pulido ${ }^{42}$, representa a uno de los grandes comerciantes. Participa durante la Guerra de los Diez Años en el tráfico de $\operatorname{armas}^{43}$. Asimismo adquiere bastante notabilidad participando en importantes comisiones y juntas políticas y mercantiles. Entrando a formar parte del Consejo Administrativo de Bienes Embargados durante la guerra. Pertenecía al «Comité español» de Cuba, a la que muchos denominaban «camarilla del Capitán General»; de la que formaban parte también Julián Zulueta, Sotolongo y Calvo. Siendo elegido en 1870, Presidente del Casino Español de La Habana ${ }^{44}$. Pedro de Sotolongo o José Suárez Argudín entre otros. El Gobierno, salvo algunas excepciones, nombra a los pertenecientes al partido ultra-conservador de la Península y esclavista de las Antillas. Los cuales pertenecen al grupo de comerciantes españoles que habían hecho sus grandes fortunas con el tráfico negrero y por sus estrechos vínculos con el gobierno colonial ${ }^{45}$ El caso más representati-

en El Siglo XIX, publicando una novela. Cifr: ZaraGOZA, Justo: Las Insurrecciones en Cuba. Apuntes para la bistoria de esta Isla en el presente siglo. Madrid, Manuel G. Hernández, 1872-1873, tomo 2, págs. 304-305 y 750 .

39 Ibidem

40 José Morales Lemus nació en Gíbara el 2 de mayo de 1808. Estudió en el Convento de San Francisco de La Habana; en Puerto Príncipe fue abogado en 1833 y ejerció en La Habana. Cifr: CABRERA, Raimundo: Op cit, págs. 320-321.

41 Ibidem

42 Mamerto Pulido había nacido en España, se trasladó a Cuba como oficial del Ejército, donde contrajo matrimonio con la hija del hacendado y acreditado ferretero Sr. Ferran, convirtiéndose en uno de los grandes comerciantes. Cifr: PIRALA, Antonio: Op cit, tomo 1, pág. 494.

43 Domingo Acebrón, $M^{a}$ Dolores: «El Tráfico de Armas durante la insurrección cespedista, 1868-1878» en Revista Tebeto. Anuario Histórico Insular de Fuerteventura. Ed. Cabildo Insular de Fuerteventura, 1990, págs. 91-131.

44 Pirala, Antonio: Op cit, tomo 1, pág. 494.

45 Torres Cuevas, Eduardo, Barcía, Carmen, García, Gloria: Op cit, págs. 411-412. 
vo es el de Julián Zulueta ${ }^{46}$ el cual es el verdadero artífice y representante del conservadurismo en $\mathrm{Cuba}^{47}$.

\section{Desarkollo de los trabajos de la Junta de Información}

Las sesiones comienzan el 30 de octubre de 1866 en los salones del edificio que ocupaba entonces el Ministerio de Ultramar en la calle de Alcalá. Las presidía el Ministro de Ultramar y Alejandro Olivan. Las reuniones son secretas.

$\mathrm{Al}$ iniciarse los trabajos de la Junta de Información, la posición del Gobierno no ofrece dudas. Los comisionados tenían completa libertad para discutir y proponer todo aquello que fuera más conveniente para la prosperidad de UItramar pero sin salirse «del círculo de la unidad nacional, la unidad católica y la unidad dinástica» ${ }^{48}$.

Sin más aplazamiento el 4 de noviembre los comisionados reciben el primer Interrogatorio, en los siguientes términos: «Sobre la manera de reglamentar el trabajo de la población de color, asiática y los medios de facilitar la inmigración que sea más conveniente en las provincias de Cuba y Puerto Rico» ${ }^{49}$. Causa mal efecto. Esperaban que todos los interrogatorios se hubieran presentado juntos, como así se les había prometido. Hubo decepción al entreveerse que el Gobierno intentaba evitar las cuestiones políticas que eran las más importantes.

Morales Lemus expresa la necesidad de conocer todo el interrogatorio para poder contestar acertadamente, puesto que todas los asuntos estaban entrelazados. Considerada por el presidente la cuestión como de forma. Se niega a los comisionados el derecho de discutir el orden de los interrogatorios. En este primer cuestionario se hace alusión a las cuestiones sobre el trabajo esclavo y la inmigración. Sin embargo, una de las más importantes las cuestiones políticas no se había presentado. El presidente Alejandro Olivan les había dicho que se estaba redactando. A pesar de todos los incidentes continuaron. Dividiéndose las sesiones en cuatro secciones: Negros esclavos, siendo designado como presi-

\footnotetext{
46 Julián Zulueta nació en Alava en 1814 emigra a Cuba en 1832 trabajando en un negocio familiar convirtiéndose en uno de los grandes comerciantes. Además como muestra de su poder controlaba como presidente la "Junta Central de Colonización»; es decir, la emigración de los extranjeros a Cuba. Expediente con motivo de la llegada de los comisionados chinos. (Comisión General de Colonización). Carta de Julián Zulueta al Gobernador Superior Político. La Habana, 24-II1874. Ministerio de Estado. Carta: firma ilegible al Capitán General de la Isla de Cuba. Madrid, 26-I-1874. Cifr: Archivo Histórico Nacional de Madrid, Sección: Ultramar, Legajo nº 3650 (1).

47 ESPADAS BuRGos, Manuel: Alfonso XII y los Orígenes de la Restauración. Madrid, C.S.I.C., Escuela de Historia Moderna, 1990, págs. 271-285.

48 VALIENTE, Porfirio: Réformes dans les Isles de Cuba et Porto Rico. Paris, Imprimiere Centrale des Chemin de Fer, 1869, pág. 50.

49 Cifr: Información sobre reformas de Cuba y Puerto Rico, tomo 1, pág. 41.
} 
dente Olivares; Negros libres, Castellanos; Población Asiática, Ramón de la Sagra; Inmigración; el Conde de Pozos Dulces ${ }^{50}$.

En la Sección de Negros esclavos una de las más importantes puesto que es una de las cuestiones más enjundiosas, los comisionados por Puerto Rico, Ruiz Belvis, Acosta y Quiñones piden la abolición inmediata de la esclavitud ${ }^{51}$. Frente a ellos, Manuel Zeno y Correa argumentan que la emancipación de los negros conllevaría el enfrentamiento de razas. A él se suma la moción presentada por los comisionados de Cuba de tendencia más reaccionaria encabezados por Joaquín Estéfani, solicitando que la propuesta no sea tomada en cuenta, en aras de la tranquilidad y del sosiego.

Manuel de Armas comisionado por el Ayuntamiento de la ciudad de La Habana, Ramón de la Sagra, el Marqués de Manzanedo o Pedro de Sotolongo, entre otros, se adhirieron, pues «les habían recomendado que sí se trataba el asunto de la emancipación no apoyaran ninguna medida violenta».

Con el apoyo de los comisionados reformistas se aprueba que el esclavo que fuera castigado cruelmente fuera liberado. En abierta oposición estaba Argudín, al argumentar que esto podría ser aprovechado por los esclavos para provocar a los blancos y obtener la libertad. Asimismo, José I. Echevarría afirmaba que no debía eliminarse el castigo corporal, sino reformar los reglamentos, respecto al número de azotes que podían darse y con que instrumentos.

Las quince primeras preguntas del Interrogatorio sobre la reglamentación de los esclavos en ambas Islas, habían sido respondidas. Una de ellas trataba sobre la posibilidad de aumentar las parroquias y la labor que ejercen los religiosos de las misiones. Esta se consideraba una medida factible debido a las condiciones topográficas de la Islas. Había que inculcar a los esclavos «el espíritu religioso, puesto que este era el único que podía lograr que èstos sobrellevaran resignados su situación, fueran humildes, trabajadores y respetuosos».

Ramón de la Sagra expone con más detalle sus razones. Partía de la base que el Gobierno de S.M apoyaba la emancipación progresiva, pues necesitaba conservar esa mano de obra. Ni las «Sociedades Abolicionistas» de Estados Unidos, Inglaterra o Francia y añadía la «plagiaria de Madrid» tenían un programa de emancipación. La Sagra se mostraba partidario de no eliminar la numerosa población esclava la cual se encontraba ya aclimatada ${ }^{52}$.

\footnotetext{
${ }^{50}$ Carta del Conde de Pozos Dulces a su hermano. Madrid 13 de noviembre de 1866 contándole como se desarrollaban los trabajos. Ibidem

51 RuIz Belvis, Segundo, Acosta, José Julián, QUIÑONES, Francisco Mariano: Proyecto para la Abolición de la Esclavitud en Puerto Rico. San Juan de Puerto Rico, Instituto de Cultura Puertorriqueña, 1959, 101 págs.

52 Datos sobre los esclavos en Cuba y la posición de los independentistas cubanos, desde el grito de Yara, ESTRADE, Paul: José Martí. Los fundamentos de la democracia en Latinoamérica. Aranjuez, Doce Calles, 2000, págs.209 y ss.
} 
Frente a esta visión más conservadora estaban los comisionados reformistas de Cuba y Puerto Rico53. En el Informe, presentado por Miguel Angulo Heredia, pedían que se declarara piratería a la trata africana, retirándoles a los contrabandistas negreros la nacionalidad española, y fueran juzgados como piratas.

En Cuba Antonio González Mendoza, abogado de notable prestigio, propuso formar una asociación semejante a las tituladas de templanza, cuyos miembros se obligaran con la garantía de su honor a no comprar bozales introducidos después del 19 de noviembre de 1865. La iniciativa fue apoyada por José Julián Acosta, Castellanos, Nicolás Azcárate, Morales Lemus, El Conde de Pozos Dulces, Antonio Rodriguez, Tomás Terry, José Antonio Echevarría, Francisco $\mathbf{M}^{\mathrm{a}}$ Quiñones, Calixto Bernal. Agustín Camejo, Ruiz Belvis y Manuel Ortega.

La asociación después de mantener algunas reuniones con peninsulares e insulares de reconocida posición social, ilustración y civismo, informó de sus proyectos al Gobernador General, obteniendo su aprobación. Sin embargo; las presiones de las «fuerzas vivas» lograron que fuera prohibida siendo acusada de tener «miras encubiertas y de atacar la unidad nacional».

En la Sección Segunda denominada de Negros Libres, los comisionados de Puerto Rico, entre los que se encontraban Acosta, Belvis y Quiñones emitieron un Informe indicando el riesgo que una legislación especial provocaría. Produciendo diferencias abismales entre los negros libres, y los esclavos. Los comisionados dudaron de la conveniencia para Puerto Rico de crear esa clase de negros libres. La población de color daba importantes beneficios a la producción y mejora del país.

Se opusieron Zeno y Argudín que con una postura muy españolista emitieron un voto particular, alegando que la propaganda revolucionaría atentaba contra los «buenos españoles».

Asimismo en los trabajos de esta Sección se tocaron otros asuntos. Por ejemplo, la posible creación de una comisión que estudiara los problemas sobre la vagancia en Cuba. Informaron los Armas, Sterling, MoralesLemus, Camejo, Azcárate y Ángulo. Sostenían que no debían existir diferencias entre las diversas razas. Rechazaban además la «desmoralizadora pena de presidio» y reclamaban la modificación del sistema penitenciario. Denunciaban los abusos cometidos por la policía, y principalmente por los capitanes de partido.

En la Sección tercera que trataba el tema sobre la Población Asiática, su presidente, Ramón de la Sagra, presenta un informe en el cual determinaba que después de finalizado el primer contrato de tres años, debía emitirse una serie de informes y de esta forma aprobar cuales podían o no quedarse en el país. Sin embargo, había que ser consciente que la colonización asiática había sido orga-

53 Los cuales eran los siguientes: José Miguel Angulo Heredia, José Julián Acosta, José de la C. Castellanos, Nicolás Azcárate, José Morales Lemus. Y se adhirieron el Conde de Pozos Dulces, Antonio Rodriguez, Tomás Terry, José A. Echevarría, Francisco M. Quiñones, Calixto Bernal. Agustín Camejo, Ruiz Belvis, y Manuel Ortega. Cifr: Información sobre reformas: Op cit, tomo 1, pág. 119.

Hispania, LXII/1, núm. 210 (2002) 141-166 
nizada en la Isla por una serie de empresas que no podían ser destruidas de repente, por consiguiente se veía factible que esta inmigración pudiera continuar por el término de tres años más.

La Sección Cuarta abordaba las cuestiones relativas a la Inmigración. La presidía el Conde de Pozos Dulce, uno de los más prestigiosos estudiosos sobre estas cuestiones. El General Serrano durante su mandato en Cuba, le había conocido y él mismo le escribiría una carta para que aceptara ser comisionado para la Junta de Información.

El Conde de Pozos Dulces tenía una postura muy clara: la inmigración más conveniente y la que es necesario estimular y apoyar es la blanca, sin distinción de nacionalidades, brindándoles las suficientes garantías un «gobierno justo, ilustrado y progresivo». «Los trabajadores y pobladores blancos fecundarán la producción de sus campos y desterrarán de ellos para siempre el sistema devastador de agricultura que allí se había entronizado con el ánimo de promover los adelantos materiales y consolidar la civilización de la raza blanca y la unión de aquellas provincias con la Metrópoli» ${ }^{54}$.

Este informe fue apoyado también por los comisionados antirreformistas; entre los que se encontraban Vicente V. Queipo, Ramón Montalvo y Calvo, Manuel de Armas, el Conde de Vallellano entre otros ${ }^{55}$; los cuales presentan la posibilidad que esta emigración fuera organizada por particulares. Suárez Argudín afirmaba que los blancos no se dedicarían al trabajo de la agricultura por ocho pesos mensuales. La situación de cualquier labrador en Europa era más deficiente. Los negros en Cuba vivían más felices. Pedía la libre entrada en $\mathrm{Cu}$ ba y Puerto Rico de todas las razas, excepto de la africana.

No obstante, se emitió un voto particular sobre la conveniencia de conservar la raza africana, pues parecía ser la más preparada físicamente para las duras labores de los ingenios y haciendas, pero caminando hacia un estado de provechosa libertad.

Pozos Dulces, como presidente de la comisión de Inmigración presenta otro informe un mes después del primero, avalado por el resto de los comisionados reformistas, Calixto Bernal, José Antonio Echevarría, Nicolás Azcárate ${ }^{56}$. La propuesta sostenía la indiscutible importancia de la inmigración blanca y el cese de la entrada de la raza de color. Para los comisionados esta solución significaba entrar en las vías de progreso y justicia, solucionando España el grave

54 Información sobre reformas: Op cit, tomo 1, págs. 155-156.

ss Además de Ignacio González Olivares, José Ignacio Echèvarría, Estefani, J. Munné, Ramón de La Sagra, Pedro de Sotolongo, Jiménez, Martínez Valdivieso, Manuel Zeno (en apoyo a Cuba), El Marqués de Manzanedo y Gerónimo Usera. Cifr: Ibidem

s6 Junto a José Miguel Angulo Heredia, Manuel de Ortega, Agustín Camejo, Tomás Terry y José Morales Lemus. Ibidem, págs. 172-215. 
problema de la esclavitud, sin llegar a comprometerse los intereses materiales. $\mathrm{Y}$ tendiendo cada vez más al blanqueamiento de la raza ${ }^{57}$.

La Junta de Información prosigue los trabajos el 11 de diciembre sobre las Cuestiones Económicas. Se nombra una comisión nueva, compuesta por Pastor, Vázquez Queipo, Azcárate, Morales Lemus ${ }^{58}$. Los puntos clave son: la abolición completa de las aduanas en ambas Islas ${ }^{59}$ y la sustitución del impuesto del $6 \%$ sobre la renta líquida. Si esto no fuera aceptado pedían la reducción de los impuestos directos y la simplificación de las tarifa, enumerando el derechos diferencial de bandera, la libertad del comercio de harinas, la liberación de todos los derechos sobre del tabaco enviado a la Península, y entre las Antillas; la supresión de las matrículas de Marina, y las ordenanzas sobre la pesca, o la construcción naval. Se solicita igualmente la abolición del diezmo y de la alcabala. Y que el comercio entre las Islas y la Península fuera de cabotaje ${ }^{60}$. Estos Informes habían sido presentados al Ministro de Ultramar, Alejandro de Castro el 30 de enero de 1867; varios días después, el 12 de febrero la Reina firma un decreto modificando los impuestos en la Isla de Cuba ${ }^{61}$. Constaba de 18 artículos. Se suprime las alcabalas de esclavos, de fincas, de ganados y de remates; el derecho de vendutas, el diezmo, la manda pía forzosa, el impuesto sobre salinas, los portazgos, el derecho único y fijo de almacenes y tiendas, las medias annatas seculares, el estanco de gallos, el derecho de consumo de ganados y de las costas procesales (art. $1^{\circ}$ ). Se fijan los derechos de exportación (art. $2^{\circ}$ ).

Pero al suprimir estos se constituyen las siguientes contribuciones: el 10\% sobre las rentas líquidas procedentes de la riqueza rústica, pecuaria y urbana y un impuesto sobre las utilidades en la industria, las artes, las profesiones y el comercio $\left(a r t .3^{\circ}\right.$ ). En Puerto Rico se aplicaría en la parte que pudiera llevarse a cabo; sin especificar nada más ${ }^{62}$.

57 Esta posición perduraría hasta 1895. José Martí quiso asegurar a todos que Cuba sería «una república abierta a la laboriosidad del mundo». Carta al Consul inglés en Guantánamo, abril, 1895. El programa del Partido Revolucionario Cubano hablaba de una emigración «preferentemente europea». Había una posición favorable a la «blanquización» de la población. Vid ESTrADE, Paul: $O p$ cit, págs. $185-187$ y $76-82$.

58 Además de Díaz Argüelles, el Conde de Pozos Dulces, Armas, Acosta, Ruiz, Echevarría, Estéfani, Terry, Sotolongo y Castellanos. Cifr: Información sobre reformas: Op cit, tomo 1, págs. 228-232.

59 Esta reclamación se debía a los continuos fraudes de numerosos empleados que habían hecho de esta forma importantes fortunas. Su puesta en práctica, Real Decreto reformando el sistema tributario de la Isla de Cuba. Palacio 12 de febrero de 1867., firmado el Ministro de Ultramar, Alejandro de Castro. Cifr: Colección Legislativa de España. Madrid, Imprenta del Ministerio de Gracia y Justicia, primer semestre, 1867, tomo 97, págs. 250-262.

60 VALIENTE, Porfirio: Op cit, pág. 85.

61 Real Decreto reformando el sistema tributario de la Isla de Cuba. Palacio 12 de febrero de 1867. Firmado el Ministro de Ultramar, Alejandro de Castro. Cifr: Colección Legislativa de España: $O p$ cit, págs. 250-262.

62 PIRALA, Antonio: Op cit, tomo 1, págs. 204-218.

Hispania, LXII/1, núm. 210 (2002) 141-166 
El Real Decreto indigna a los comisionados que protestan y piden que se suspenda su publicación en las Antillas. Mostrándose unánimes al afirmar que no debían introducirse cambios en el sistema de impuestos, y menos establecer una nueva contribución directa. Mientras «aquellos españoles» no pudieran ejercer su derecho a votar los presupuestos, no hubiera provincias y diputaciones provinciales, y se frenara la centralización administrativa.

Una vez más quedaba de manifiesto como el sistema explotación iba a continuar. La Metrópoli insensible ante las quejas de los comisionados pretendía seguir gobernando a las Islas por «ordenes reales». El decreto ni siquiera había sido enviado a las Cortes para su aprobación. Queda de manifiesto el talante de las autoridades españolas, que una vez más ejercitaban de forma inexorable el poder sobre sus colonias.

Por fin llega el momento de debatir el Interrogatorio político. Siendo la cuestión principal para los reformistas. Había que establecer dentro de la «unidad nacional la variante de formas", es decir las leyes especiales constitutivas. Sus bases, que no hubiera diferencias legales entre los españoles. La importancia de este Interrogatorio era clave, puesto que sin él, no podían realizarse las reformas sociales, económicas, o administrativas. Formándose una comisión para redactar un informe, de la que van a formar parte, el Conde de Pozos Dulces, Ruiz, Saco o Bernal, etc. ${ }^{63}$

Los comisionados José Antonio Saco y Calixto Bernal elaboraron sendos informes detallados. Saco, a pesar de haber apoyado la presencia física de los diputados cubanos en las Cortes en Madrid; siendo él mismo uno de ellos, cambia su postura en 1867. Con la tesis de que «la entrada en las Cortes de los diputados ultramarinos podría perpetuar la centralización en Madrid de los negocios que debían resolverse en Cuba y Puerto Rico».

¿Qué beneficios obtuvieron Arango, Varela, Santos Suárez o Tomás Gerner, cuando fueron diputados, desde 1812 hasta 1822? Los tres últimos presentaron proyectos para crear Diputaciones provinciales con competencias políticas, entre ellas, revocar leyes que perjudicaran los intereses de las Islas y destituir a aquellos gobernadores que se excedieran en sus atribuciones. Esto no sería aceptado en Madrid. Después en 1823 con la restauración absolutista, las Cortes no se reunieron hasta 1834.

En 1837 Saco presenta la posibilidad de establecer una Junta provincial colonial. La idea era que las provincias de Ultramar pudieran tener constituciones particulares; las cuales defendieran los derechos y las garantías de sus habitantes; propusieran las leyes y los presupuestos que iban a regirles... A la vista de los resultados, Saco estaba persuadido en 1867 de la ineficacia de la elección de diputados... ise escucharían sus proyectos, o por el contrario se considerarían inútiles e inoportunos y hasta contrarios a los intereses de la Metrópoli?

63 Otros miembros de la comisión Armas, Vázquez Queipo, Morales Lemus, Olivares, Acosta; Zeno, Castellanos, Angulo, y Echevarría. Cifr: Información sobre reformas,: Op cit, tomo 2, págs. 33-44. 
Había otro peligro: que algunos diputados olvidaran "sus deberes y convirtieran «este cargo en escabel de sus personales pretensiones».

A favor de esta tesis comparaba España con otras potencias colonizadoras como. Gran Bretaña y Holanda, las cuales habían establecido para sus colonias "Cartas e instituciones libres»; y nunca habían tenido diputados nativos en las Cortes ${ }^{64}$.

Bernal al igual que Saco, mantenía que para defender los intereses de las colonias no era necesaria la presencia física de los diputados en Madrid. Sería más eficaz la existencia de Corporaciones o Diputaciones insulares, con delegados o comisionados, cuya misión sería proponer a las Cortes, las leyes más convenientes para las colonias, y que estas fueran aprobadas. Esto era en definitiva, la asimilación.

El resto de los comisionados reformistas entre los que se encontraban el Conde de Pozos Dulces, Morales Lemus, Tomás Terry, Acosta o Ruiz Belvis...en las respuestas al Interrogatorio político, propugnaban la importancia de dichas Corporaciones insulares, para la descentralización del Gobierno. En el ámbito jurídico pedían que todos los asuntos pudieran resolverse en las propias islas. Y la separación del mando civil y militar; desde los gobernadores superiores, teniente gobernador, a los alcaldes, capitanes pedaneos de las pequeñas poblaciones $^{65}$. Las acusaciones de los antirreformistas de que este proyecto provocaría la emancipación de las colonias que le quedaban a España; era bastante errónea pues únicamente se estaban exponiendo reformas en importantes ámbitos de la Administración, pero sin abordar en ningún momento de estos trabajos la separación o independencia de la Metrópoli.

El General Serrano se había mostrado ya partidario de la separación del gobierno civil y militar. Comprendía que «las quejas de los cubanos eran justas y sus aspiraciones legítimas...en Cuba regía un gobierno militar y absoluto...; sin prensa, sin representación alguna en el Gobierno, sin una sola garantía de las existentes en la Península...»66.

Por último, se examina el asunto más espinoso de esta Junta de Información el tema de la Abolición de la esclavitud. Los comisionados reformistas de Puerto Rico presentan un amplio Informe. Piden la abolición de la esclavitud, con indemnización o sin ella; la abolición sin reglamentación del trabajo libre o con ella. Su argumento se basaba en conceptos morales y en intereses materiales. Puerto Rico no necesitaba esa institución para su riqueza general. Su desaparición no afectaría a ninguna fuerza productora. Las cifras eran elocuentes. De cuarenta mil esclavos, sólo diez mil realizaban trabajos agrícolas, mientras más de setenta mil proletarios libres, blancos o negros, trabajaban en las plantaciones. La conclusión que se desprendía es que la mayor parte de la elaboración de azúcar se obtenía con brazos libres ${ }^{67}$.

\footnotetext{
64 Cifr: Información sobre reformas: Op cit, tomo 2, págs. 45-87.

65 Información sobre reformas: Op cit, tomo 2, págs. 100-143.

66 Pirala, Antonio: Op cit, tomo 1, págs. 210-211.

67 Valiente, Porfirio: Op cit, pág. 53.
}

Hispania, LXII/1, núm. 210 (2002) 141-166 
Acosta, Ruiz Belvis y Quiñones autores del Informe que titularon «La abolición de la esclavitud era una necesidad política...», exponían como estaba todavía muy reciente la guerra de Secesión en Estados Unidos, pudiendo abrirse un conflicto internacional que seria para "la raza blanca la causa de una sangrienta lucha...en las Antillas... ${ }^{68}$.

El puertorriqueño Zeno y el cubano Armas se opusieron a este Informe. Armas consideraba imposible indemnizar a todos los propietarios de esclavos. Había en ambas Antillas de 402.280 esclavos. Tasado cada uno en 4.000 francos la suma alcanzaría la cantidad de 1.649.164.000 francos Era imposible sufragarse ${ }^{69}$. La abolición en Cuba debía ser gradual.

Los comisionados reformistas cubanos presentaron un Informe exponiendo las razones políticas y sociales que aconsejaban la abolición. La forma de llevarla a cabo tendría que ser diferente a la de Puerto Rico, pues no eran idénticas las condiciones sociales y políticas. Sus tesis eran, sin embargo muy parecidas a las de los puertorriqueños. Políticamente, la emancipación que se había producido en todas las repúblicas hispanoamericanas; incluso el imperio de Brasil se preparaba para realizarla. En todas las colonias de los paises europeos Inglaterra, Francia, Suecia, Holanda, Dinamarca, y en Estados Unidos. Asimismo el virrey de Egipto, el bey de Túnez había abolido la esclavitud en sus dominios. No debería olvidarse la catástrofe de Haití. España se había quedado como la única nación europea que mantenía el sistema esclavista. Por eso el Congreso federal de Estados Unidos había propuesto «el bloqueo moral de todo el mundo civilizado contra España».

Expusieron además argumentos de tipo racial. Convivían en Cuba dos razas antagónicas, que podrían entrar en conflicto ${ }^{70}$. Para conseguir la abolición en Cuba se presentaba un Plan de emancipación gradual. Incluía como puntos básicos: primero, la supresión de la raza africana; segundo, la indemnización a los poseedores de esclavos; tercero, el establecimiento en La Habana de un «Banco de depósito, prestamos y descuentos de crédito hipotecario y agrícola», que estuviera facultado para emitir billetes ${ }^{71}$.

A pesar de todo el talante de los comisionados había sido bastante conciliador, las peticiones o quejas presentadas tenían como objetivo obtener reformas políticas o administrativas. Acercaba aún más la posibilidad de una transformación social y dejaban claro sus pretensiones... «en la confianza de que Cuba podría superar esta situación sin dejar de ser española y civilizada para ser africana y bárbara». Este Informe había sido firmado por Antonio Rodriguez Ojea,

\footnotetext{
68 Proyecto para la abolición de la esclavitud en Puerto Rico: Op cit, págs. 20-66.

9 Valiente, Porfirio: Op cit, pág. 56.

Información sobre reformas: Op cit, tomo II, págs. 287-301.

Información sobre reformas: Op cit, tomo II, págs. 287-288.
} 
Azcárate, José Antonio Echevarría ${ }^{72}$. Adhiriéndose los comisionados de Puerto Rico, Acosta, Ruiz Belvis ${ }^{73}$.

Para cubanos y puertorriqueños, como se desprende en la exposición de sus peticiones, «la raza» era una preocupación fundamental. Los comisionados que vienen a Madrid ¿pedían la abolición de la esclavitud como algo que significaría un cambio radical en la vida de los esclavos negros, o simplemente se abordaba la cuestión como un asunto que podría poner en peligro la preponderancia de la «raza blanca»? De ahí sus alusiones al peligro que podría suponer la catástrofe de Haití. El tema de la «raza» lo habían abordado algunos de los comisionados en sus escritos. El Conde de Pozos Dulces, titula sus cartas escritas desde París y publicadas en Cuba en El Correo de la Tarde, «Son causas morales, no físicas las que principalmente alejan al hombre blanco de la agricultura tropical». En ellas se pregunta «¿Por qué no pueden los blancos reemplazar a los negros, o chinos en aquellas tareas?» La respuesta estaba en el propio título de la carta...»Son causas de orden moral».

«Mientras más se eleva una raza en la escala de la civilización más se aparta de aquella especie de automatismo, que es casi patrimonio de las razas incultas y salvajes. Por ignorante que sea el hombre blanco necesita otros estímulos, tiene además un sentimiento más acentuado de la dignidad; sentimiento que es nulo es las razas inferiores...Careciendo estas de ambición e iniciativa sin más aspiraciones que la de matar el hambre, o la de evitar el castigo. Son más propias para convertirse en instrumentos mecánicos de voluntad ajena. Faltan pues al colono o inmigrante blanco los principales estímulos. El recuerdo de su patria; amigos; familia; la nostalgia de que son incapaces las razas de color... ${ }^{74}$

La Junta de Información concluye sus trabajos el 27 de abril de 1867; después de cinco meses y treinta y seis sesiones de trabajo. Fue disuelta por Narvaez ${ }^{75}$, pometiendo el Ministro de Ultramar, Alejandro de Castro, leer con detenimiento todos los informes, y solucionar la situación de las Antillas ${ }^{76}$.

No hubo secretarios que tomaron actas de las discusiones y debates; se prohibió a la prensa la impresión y publicación de las deliberaciones ${ }^{77}$. El secre-

72 Además de José de la Cruz Castellanos, José Morales Lemus, José Miguel Angulo Heredia, El Conde de Pozos Dulces, Manuel Ortega, Agustín Camejo, Calixto Bernal y Tomás Terry (que apuntaría algunas discrepancias con los anteriores) y Gerónimo Usera. Cifr: Información sobre reformas, Op cit, tomo II, págs. 257-301. Sobre el tema del racismo en Cuba ver el libro de NARANJO Orovio, Consuelo: Racismo e inmigración en Cuba en el S. XIX. Madrid, Doce Calles, 1996, 236 págs.

73 Cifr: Ibidem

74 FrIAS Y JACOTT, Francisco, Conde de Pozos Dulces: Colección de Escritos sobre Agricultura, Industria, Ciencias y otros ramos de interés para la Isla de Cuba. París, Imprenta tipográfica de Jorge Kugelmann, 1860 , tomo 1 , págs. 348-353.

75 TORRes Cuevas, Eduardo, BarCia, Carmen y García, Gloria: Op cit, pág. 457.

76 MORALES Y MORALES, Vidal: Op cit, 35 págs.

77 Proyecto para la abolición de la esclavitud en Puerto Rico: Op cit, pág. 19.

Hispania, LXII/1, núm. 210 (2002) 141-166 
tismo que había rodeado a estos trabajos provoca que Ramón de la Sagra, al desvelar algunos de los resultados, fuera despedido de su empleo ${ }^{78}$.

\section{CAUSAS DEl FRACASO}

En la Junta de Información quedaron evidenciadas según Pirala, dos tendencias en Cuba: la reformista y la separatista; esta última en minoría, estaba protagonizada por José Morales Lemus, que se uniría a comienzo de la guerra a las filas independentistas. Lemus era un reformista convencido que aspiraba a la independencia de Cuba del colonialismo español. En una de sus últimas intervenciones antes de abandonar Madrid, dijo: «Sí tuviéramos la desgracia de ver desatendidas las justas aspiraciones de nuestras provincias y torcidamente interpretada y calificada nuestra patriótica solicitud, lo sentiremos profundamente, no ya por nosotros mismos, sino porque así se retardaría el bienestar de aquellos países, con perjuicio de la gran nacionalidad a que pertenecen, y como miembros de ella, deploraremos con que motivo tengan tal vez los hechos a demostrar que hubiera sido más conveniente examinar nuestras respuestas con menos prevenciones ${ }^{79}$

Reflejo del fracaso de la Junta de Información fue el desprestigio que sufrió en Cuba el periódico El Siglo, cuya dirección había vuelto a tomar Pozos Dulces. Sus desavenencias con José de Armas y Céspedes, hicieron que este abandonara el periódico, y fundara $E l$ Occidente ${ }^{80}$.

Para Piñeyro los trabajos de la Junta de Información no interesaron ni a los cubanos ni a los puertorriqueños. En Cuba "existía un deseo sincero de reformas al abrigo de España. Y si estas se hubieran otorgado a muchos hubiera dejado satisfechos. El problema cubano si no definitivamente resuelto si hubiese perdido su más grave carácter. La situación nunca volvería a ser la misma ni en Cuba ni en España» ${ }^{81}$.

Algunos de los que habían participado ofrecieron testimonios muy desalentadores. Calixto Bernal, de la escuela de Saco, escribe: «acabó la misión de la palabra: ha sonado la hora de conquistarlo todo con la espada». Morales Lemus, jefe del comité directivo de El Siglo, aceptaría el cargo de Ministro Plenipotenciario en Estados Unidos de la naciente «República cubana». El Conde de Pozos Dulces se refugiaría en París, donde muere años más tarde ${ }^{82}$.

78 Encontrándose en una situación muy precaria y de miseria, tuvo que emigrar a Ginebra a casa de un amigo donde murió. MORALES y MORALES, Vidal: $O p$ cit, 35 págs.

79 PIRAla, Antonio: Op cit, pág 217.

80 MORALES y MORALES, Vidal: Op cit, 35 págs.

81 PIÑEYRO, Enrique: Op cit, págs. 21-24.

82 De LA CRUZ, Manuel: Cromitos cubanos. La Habana, Establecimiento Tipográfico La Lucha, 1892, págs 327-328. Ver también: Domingo AcEBRóN, $M^{a}$ Dolores: «Los Reformistas cubanos en París, 1837-1878» en Caravelle, Toulouse, n 74, 2000, págs. 105-117. 
Porfirio Valiente, uno de los pocos que publica un estudio detallado sobre lo que ocurrió tres años después, ponía de manifiesto como los resultados de tantos esfuerzos habían sido desoladores. Los delegados de Cuba ni habían sido escuchados ni sus trabajos consultados. "Heridos en su dignidad veían la continuación del sistema de explotación con el derecho de gobernar la Isla por ordenes reales».

La negativa por penúltima vez a las peticiones de los antillanos se iba a interpretar en los círculos más concienciados políticamente en Cuba y Puerto Rico, como el final de un proceso... que conduciría a luchar por la independencia. Sus reflexiones muy lúcidas no dejaban duda de una situación verdaderamente insostenible. "El sistema actual es la negación de todo derecho individual. Un gobierno autónomo en Cuba y Puerto Rico, como una variedad constitucional de la Madre Patria es una necesidad demostrada por la razón y la experiencia. No acordar las instituciones políticas particulares y adaptadas a las condiciones físicas, políticas y sociales de estos paises equivalía a la separación de la nacionalidad española.» ${ }^{83}$

Los trabajos de la Junta de Información iniciados con el gobierno de la Unión Liberal, continuaron con uno del partido moderado. Es decir, en unos meses después de arduos e intensos trabajos que había sido tomados aparentemente con notable interés, se responde a los comisionados con un nuevo impuesto en Cuba.

Hubo quienes dudaron del sentido patriótico de algunos comisionados a la luz de los sucesos posteriores, pues «se habían tomado como pretexto las reformas para apresurar el advenimiento de la independencia» ${ }^{84}$. No parece muy creíble puesto que como ya ha quedado de manifiesto, de los que participaron en la Junta de Información sólo Morales Lemus y Bramosio, tomarían partido por el movimiento independentista de 1868.

¿Tuvo España verdadero interés en promover esas reformas, o simplemente fue un nuevo golpe de efecto, para intentar acallar las quejas de los antillanos? O por el contrario ¿había por parte de Canovas una predisposición para resolver los problemas de las colonias? ¿Había sido la Junta de Información una propuesta personal o le presionaban las circunstancias políticas?

Al comienzo de los trabajos queda clara la postura inflexible de las autoridades españolas. Uno de los informes presentados por los miembros nombrados por el Ministerio, abordaba el artículo 80 de la Constitución: «Las provincias de Ultramar serán gobernadas por leyes especiales». Para Porfirio Valiente, este texto excluía del sistema constitucional español a las dos islas. Y se proclamaba que la asimilación política era de todo punto de vista imposible, debido a la diversidad de razas... Se proponía como alternativa la creación del Consejo de las Antillas; integrado por los diputados elegidos en ambas islas y por un número igual de personas designadas por la Corona. Los requisitos para ser

83 Valiente, Porfirio: Op cit, págs. 90-94.

84 Palabras de Enrique Piñeyro, PIRAlA, Antonio: Op cit, tomo 1, pág. 216.

Hispania, LXII/1, núm. 210 (2002) 141-166 
miembro de este Consejo era haber residido dos años en las Antillas y tener unas rentas de 7.500 écus en Cuba, 5.000 en Puerto Rico y 3.000 en la Península. $\mathrm{O}$ en su caso haber ejercido el cargo de Comandante militar equivalente al grado de General; o haber sido jefe superior de la Administración, director general o subsecretario en Ultramar ${ }^{85}$. Requisitos bastante difíciles de cumplir por la mayoría, quedando limitado a un grupo muy reducido. La intención de las autoridades españolas quedaba muy clara. Pretendía un control férreo de la situación. Es decir, mantenimiento del «statu quo». Como órgano consultivo informaría al Gobierno para que fuera aprobado en las Cortes cualquier asunto relativo a Ultramar.

Otro asunto espinoso y fundamental, las atribuciones del Gobernador General las cuales iban a continuar inalterables. Bajo sus órdenes las fuerzas de mar y tierra, sin confundir las atribuciones militares con las civiles. Entre estas, estaban el nombramiento de todos las autoridades y empleados subalternos; excepto los que eran de nominación real; declaración del estado de sitio; y otras menos destacadas. Parecía inexorable que los abusos de poder del Capitán General volverían a enturbiar la vida cotidiana en las colonias.

De esta forma, y a la vista de las pretensiones de las autoridades metropolitanas no fue posible obtener las reformas ansiadas por Cuba y Puerto Rico; sí España mantenía inalterable la estructura política y social en el gobierno de las colonias. La prepotencia había sido la actitud de la mayoría de los Capitanes Generales, salvo algunos, cabe la excepción de los Generales Serrano, Dulce.

No obstante, a la vista del significado la Junta de Información, su fracaso se debe según Rafael María de Labra, uno de los más acerrimos defensores de las reformas en las Antillas, a diversas causas. En primer lugar, el Gobierno, había designado con sólo una o dos excepciones, a personas de tendencia ultraconservadora y esclavista. Fue una decisión de poca habilidad que generó enfrentamientos con la mayoría reformista representada por los antillanos. Entre estos había posiciones más o menos moderadas Porfirio Valiente, mantenía una oposición intransigente hacia España, y una exagerada devoción hacia la democracia de los estados del sur de Estados Unidos ${ }^{86}$.

Pero por supuesto, no cabe aquí justificar el fracaso de la Junta de Información, por las tendencias políticas de los integrantes.Había quedado de manifiesto desde el comienzo de los trabajos el desinterés de las autoridades españolas para abordar las reformas en las colonias. Sino como se explicaban la imposición de nuevas cargas fiscales.

En definitiva, la decepción de los comisionados reformistas antillanos fue total la respuesta del Ministerio de Ultramar fue la de «lo estudiaremos». Su re-

85 VALIENTE, Porfirio: Op cit, pág. 125.

86 LABRA; Rafael $\mathrm{M}^{\mathrm{a}}$ : La libertad de los negros en Puerto Rico. Sin lugar, sin editorial, sin fecha, págs. 32-35. 
sultado más inmediato: la creación de una contribución directa con una cuota doble de la propuesta por los comisionados y la negativa de abolir las aduanas.

Por consiguiente, ¿por qué se asombraron las autoridades españolas de la insurección de Yara? Eran conscientes de que habían entorpecido un proceso político que podría haber tenido «tal vez» otras consecuencias, si se hubieran escuchado e intentado resolver las quejas de los antillanos. ¿No era compresible que los puertorriqueños, expusieran como algo prioritario, la abolición de la esclavitud, antes que hablar de reformas administrativas, o políticas?

Intransigencia, ineptitud para abordar los problemas de las colonias. Demasiados intereses en juego, defensa del mantenimiento del «statu quo»; e incluso desconocimiento de la situación real de lo que ocurría en Ultramar. Todo esto hizo imposible examinar con éxito la cuestión colonial.

En 1866 los antillanos que vienen a Madrid tenían una actitud tolerante y moderada; y que esta sería la ultima oportunidad para haber solventado las cuestiones que más preocupaban tanto en Cuba como en Puerto Rico; antes de la explosión de la guerra de tendencia independentista, la Guerra de los Diez Años, (1868-1878); primera de las tres que habrían de sufrir cubanos y españoles.

\section{APÉNDICE No ${ }^{\circ}$. EXPOSICIÓN DE LOS REFORMISTAS A S.M, EL 28 DE JULIO DE $1865^{87}$.}

Señora los que suscriben, naturales de la Isla de Cuba, o residentes en ella, comprendidos en la nacionalidad española exponen...Sin mandato especial para representar a todos los habitantes del país, porque no lo consiente su organización política, creen sin embargo conocer bastante bien las aspiraciones de la mayoría...

Las Antillas españolas y principalmente Cuba, han llegado a un punto envidiable de prosperidad material, debido a su posición geográfica, la fertilidad de su suelo, a las emigraciones de los países vecinos, a la no interrumpida paz de que ha gozado y a la acción del Gobierno, que concedió desde principios del siglo franquicias económicas, desarrollándose la actividad de sus habitantes, y con ella la ilustración y riqueza. Pero la expulsión de los diputados en 1837. Acostumbradas las Antillas a estimarse en todo como provincias integrantes de la Monarquía, con los mismos derechos que las demás sintieron hondamente aquella medida...A partir de entonces hubo un malestar en el país, desconfianza de las autoridades locales, odios del provincialismo, los destierros, los suplicios...

No es cierto que los habitantes de Cuba se hallen en su gran mayoría contrarios a las reformas: la verdad es que las anhelan y necesitan de todas clases;

87 La Exposición sería apoyada por numerosos hacendados cubanos residentes en Madrid; por los Generales Serrano y Dulce y por influyentes personalidades.

Hispania, LXII/1, núm. 210 (2002) 141-166 
pero dando prioridad a los derechos políticos, como origen, suma y garantía de todas las demás libertades...

Los que aparentando aplazarlas se oponen a las reformas políticas procuran alarmar con el recuerdo de los antiguos Virreinatos...Y si un siglo antes se hubieran puesto los medios de intentar sostener un sistema incompatible con los adelantos y las necesidades de los pueblos puede que hoy ondease la bandera de Castilla...

Forzoso es decirlo pasado ya el tiempo en que Cuba y Puerto Rico temblaban la idea de llegar a ser africanas: empero por lo mismo que conocen los gérmenes de su riqueza y de civilización; saben también que es necesario la poderosa égida de la nación para conservarlos y adelantarlos con beneficio de la raza y la patria comunes, y que no podrán hacerlo si no se atiende a sus justas reclamaciones...Su deseo de verse reintegrados en el derecho de España; es ser españoles en plenitud de derecho... Exposición de los reformistas a S.M. Ultramar, 28-VII-1865. Cifr: Información sobre reformas de Cuba y Puerto Rico. Nueva York, Imprenta de Hallet y Breen, 1867, tomo 1, 318 págs, tomo 2, 330 págs (unidos en un solo volumen). Tomo 1, Introducción págs LVII-LXII. 